\title{
DIMENSÃO PROCEDIMENTAL NA AVALIAÇÃO DA APRENDIZAGEM EM EDUCAÇÃO FÍSICA ESCOLAR'
}

\author{
Margarida do Espírito Santo Cunha Gordo² \\ Renan Santos Furtado3 \\ Christiani Lourdes Melo Newar ${ }^{4}$
}

\begin{abstract}
RESUMO
O objetivo deste artigo é construir um protocolo avaliativo como proposta de avaliação da aprendizagem para a área da Educação Física escolar, de acordo com a dimensão procedimental, tendo a Base Nacional Comum Curricular (BNCC) norteando esse processo de construção. Listamos, como objetivos específicos, realizar uma revisão teórica sobre a avaliação da aprendizagem em Educação e na Educação Física, sob a perspectiva da dimensão procedimental; identificar instrumentos e formas de avaliação da aprendizagem com base nas dimensões procedimentais; e construir o protocolo avaliativo conforme o referencial teórico estudado e a BNCC. Ressaltamos que esse protocolo deve ser entendido como um norte, um orientador e não como algo fechado e condensador de todo conhecimento que o aluno pode adquirir em relação ao conteúdo trabalhado. Cada docente deverá adequar esse protocolo de acordo com a realidade e as vivências de seus alunos. Outrossim, ele deve funcionar como uma referência se o aluno alcançou ou não os objetivos de aprendizagem do conteúdo trabalhado, com o intuito de que o professor possa ter um diagnóstico da aprendizagem para intervir de forma propositiva para que 0 discente consiga apreender os conhecimentos inerentes a esse conteúdo.
\end{abstract}

Palavras-chave: Avaliação da aprendizagem em Educação Física. Avaliação procedimental. Protocolo de avaliação. BNCC-Educação Física.

\footnotetext{
1 Contou com o apoio do Programa Institucional de Bolsas de Iniciação Científica e de Desenvolvimento Tecnológico e Inovação, vinculado à Pró-Reitoria de Pesquisa da Universidade Federal do Pará - PIBIC/ PROPESP/UFPA, destinando bolsa de iniciação científica para a bolsista do projeto.

2 Doutorado em Educação pela UNICAMP. Docente da Universidade Federal do Pará (UFPA). Brasil. Grupos de Pesquisa: Laboratório de Estudos sobre Arte, Corpo e Educação LABORARTE/UNICAMP e Grupo de Pesquisa em Práticas Pedagógicas Para o Ensino na Educação Básica - GPRAPE/UFPA. Coordenadora de projeto aprovado pelo Edital PIBIC/UFPA. Orcid iD: https://orcid.org/0000-0001-9507-6726. E-mail: margaridagordo@yahoo.com.br

3 Doutorando em Educação pela Universidade Federal do Pará (UFPA). Docente da UFPA. Brasil. Grupo de Pesquisa: Centro Avançado de Estudos em Educação e Educação Física CAÊ. Orcid iD: https://orcid.org/0000-0001-7871-2030. E-mail: renan.furtado@yahoo.com.br

${ }^{4}$ Graduanda em Licenciatura em Educação Física pela UFPA. Brasil. Bolsista do Programa Institucional de Bolsas de Iniciação Científica e de Desenvolvimento Tecnológico e Inovação da Universidade Federal do Pará - PIBIC/UFPA. Orcid iD: https://orcid.org/0000-0002-2603452X. E-mail: christianinewar@gmail.com
} 


\title{
PROCEDIMENTAL DIMENSION IN THE EVALUATION OF LEARNING IN SCHOOL PHYSICAL EDUCATION
}

\begin{abstract}
The objective of this paper is construct assessment protocol as proposal of learning assessment in the field of Physical Education at schools, considering the procedural dimension, guided by the National Common Curricular Base (BNCC). We present as specific objectives: conduct a theoretical review on the assessment of learning in Education and Physical Education, in perspective of the procedural dimension; recognize deeds and shapes of learning assessment based in procedural dimensions; and build the evaluative protocol according to the theoretical framework studied and the BNCC. We emphasize that this protocol need understood as a north, a guide and not as something closed and condenser of all knowledge that the student can acquire in relation to the school subject worked on. Each teacher must adapt this protocol according to the reality and experiences of his students. Furthermore, he needs function like a reference if the student achieved the learning objectives of the school subject worked or not, in order that the teacher can have a diagnosis of the learning to intervene in a purposeful way so that the student can learn the knowledge inherent to this school subject.
\end{abstract}

Keywords: Learning assessment of Physical Education. Procedural assessment. Protocol of assessment. BNCC-Physical Education.

\section{DIMENSIÓN PROCEDIMENTAL EN LA EVALUACIÓN DEL APRENDIZAJE EN LA EDUCACIÓN FÍSICA ESCOLAR}

\section{RESUMEN}

El objetivo de este artículo es construir como propuesta de evaluación de los aprendizajes para el área de Educación Física en la escuela, según la dimensión procedimental un protocolo de evaluación, teniendo la Base Curricular Nacional Común (BNCC) guiando este proceso de construcción. Enumeramos como objetivos específicos, realizar una revisión teórica sobre la evaluación de los aprendizajes en Educación y Educación Física, desde la perspectiva de la dimensión procedimental; identificar los instrumentos y formas de evaluación de los aprendizajes a partir de las dimensiones procedimentales y construir el protocolo de evaluación a partir del marco teórico estudiado y las BNCC. Insistimos en que este protocolo debe entenderse como una guía, una pauta y no como algo cerrado y condensador de todos los conocimientos que el alumno puede adquirir en relación con los contenidos trabajados. Cada profesor debe adaptar este protocolo según la realidad y las experiencias de sus alumnos. Además, debe funcionar como referencia si el alumno ha conseguido o no los objetivos de aprendizaje del contenido trabajado, con el fin de que el profesor pueda tener un diagnóstico del aprendizaje para intervenir de forma propositiva para que el alumno aprenda los conocimientos propios de este contenido.

Palabras clave: Evaluación del aprendizaje en Educación Física. Evaluación procesal. Protocolo de evaluación. BNCC-Educación física. 


\section{INTRODUÇÃO}

[...] essencial à educação. Inerente e indissociável enquanto concebida como problematização, questionamento, reflexão sobre a ação. Educar é fazer ato de sujeito, é problematizar o mundo em que vivemos para superar as contradições, comprometendo-se com esse mundo para recriá-lo constantemente. Um professor que não avalia constantemente a ação educativa, no sentido indagativo, investigativo do termo, instala sua docência em verdades absolutas, pré-moldadas e terminais. (HOFFMANN, 1991, p 17).

A avaliação tem papel preponderante para o processo de ensinoaprendizagem, porém, é também tema de intensos e controversos debates nas áreas da Educação e Educação Física. Segundo Darido (2012), em geral, quando se fala em avaliação, logo se tem a ideia de atribuição de notas ou de conceitos, ou mesmo se pensa em aprovação ou reprovação escolar. Como primeira aproximação conceitual, pode-se entender a avaliação como um processo que encontra sentido na potencialização de aprendizagens, devendo ser um trabalho colaborativo entre professor, aluno e escola (HOFFMANN, 2018).

É interessante destacar que o campo da avaliação apresenta uma série de tendências e preocupações teórico-metodológicas. Como exemplo, podemos citar desde a discussão a respeito da falta de conexão entre avaliação e objetivos de aprendizagem em diversas teorias pedagógicas (FREITAS, 1994); perpassando pelo debate referente às técnicas e práticas de avaliação (LIBÂNEO, 1994); até a crítica a um processo bancário de ensino e avaliação (FREIRE, 2017); estendendo-se à "contraposição básica entre uma concepção classificatória de avaliação, que se resume a julgar resultados, e a concepção de avaliação mediadora de ações pedagógicas reflexivas" (HOFFMANN, 2018, p. 17); bem como por uma "arquitetura da avaliação classificatória e crítica" (MATOS; SCHULER, 2019, p. 408). Assim, pode-se constatar a diversidade de enfoques teóricos e perspectivas no estudo da avaliação da aprendizagem no campo da Educação. 
Observa-se que, ao menos no campo da produção de conhecimento, tem-se uma densa crítica às perspectivas tradicionais e mecânicas de avaliação. Como bem pontuado por Matos e Schuler (2019, p. 405), "as instituições escolares atravessam o disciplinamento dos corpos e o controle dos públicos, por meio de inúmeras técnicas de poder, dentre elas, talvez uma das mais imperativas seja a avaliação". Desse modo, os autores afirmam que existe uma correlação direta entre a lógica disciplinar e de controle do corpo, presente na sociedade e nas escolas, com os dispositivos de avaliação da aprendizagem, que invariavelmente atuam a favor dos processos de subjetivação dominantes.

Nesse sentido, devemos estar atentos aos desdobramentos e nuances que transitam e permeiam a avaliação da aprendizagem na escola. Se é verdade que toda ação pedagógica é também direta ou indiretamente vinculadora de alguma concepção ético-política (FREIRE, 2008), seria equivocado pensarmos que a avaliação da aprendizagem pode ser um espaço de preservação da dimensão técnica da educação, sem nenhuma implicação político-social. Essa questão, quer dizer, da politicidade da educação, ganha novos contornos quando tratamos da área da Educação Física, que historicamente é associada à falta de criticidade.

Todavia, principalmente a partir do Movimento Renovador5, a discussão teórica na área da Educação Física passou a ser mais denunciativa à sua tradição ligada ao exercitar-se para (exercitar-se para a saúde, exercitar-se para a formação moral, exercitar-se para a formação do homem integral etc.) (GONZÁLEZ; FENSTERSEIFER, 2009). Como desdobramento, começou-se a questionar o modelo de avaliação

\footnotetext{
${ }^{5}$ Por Movimento Renovador da Educação Física, compreende-se um conjunto de iniciativas políticas, epistemológicas e pedagógicas que, a datar do final da década de 1970 , passaram a questionar toda a tradição da Educação Física baseada na medicina de caráter higienista, no militarismo e no esporte de alto rendimento. Como reivindicação central do movimento, teve-se a busca pela consideração da Educação Física como componente curricular da Educação Básica, tendo em vista a superação do seu então papel de mera atividade. Do ponto de vista do campo acadêmico, o movimento foi fundamental para que a área da Educação Física passasse a se imbricar de discussões oriundas das Ciências Humanas, sendo esse um aspecto decisivo na histórica recente da Educação Física no Brasil.
} 
denominado por Faria Júnior e Farinatti (1992) e reafirmado por Soares et al. (1992) de docimológico clássico. Nesse modelo, o aluno é pensado como um indivíduo a ser mensurado, sendo o centro do processo os métodos e as técnicas empregadas por via de testes, materiais e sistemas que classificam e selecionam em decorrência de graus de desempenho em atividades esportivas e motoras.

Cabe dizer que, além do avanço do campo acadêmico e da consequente ampliação dos referenciais teóricos que passaram a circular na Educação Física a partir da emergência do Movimento Renovador, surgiram propostas pedagógicas identificadas com o debate do campo da Educação e ancoradas em teorias das Ciências Humanas (DARIDO, 2003). Com isso, projetando a superação da perspectiva de avaliar para mensurar somente qualidades físicas, motoras ou a execução de gestos técnicos das modalidades esportivas, passou-se a pensar na possibilidade de a avaliação nas aulas de Educação Física ser parte de um projeto de reconstrução do significado das experiências corporais, intencionando o pleno aprendizado e a reflexão crítica sobre o universo das práticas corporais (DARIDO, 2012).

Considerando as várias formas, metodologias e instrumentos que se apresentam como possibilidades no processo de avaliação da aprendizagem, nesta pesquisa, optou-se em abordar a avaliação por sua dimensão procedimental, evidenciando que as demais dimensões, como a conceitual e a atitudinal, fazem parte de um mesmo processo, logo, no fazer pedagógico, as três não devem se dissociar. Entretanto, fizemos essa opção para estudarmos mais a fundo a dimensão procedimental, pois se trata de um tema caro para a Educação Física escolar avaliar o saber-fazer.

De acordo com Venturini (2010, p. 1), a dimensão procedimental "diz respeito ao saber fazer, à capacidade de mover-se numa variedade de atividades motoras crescentemente complexas de forma efetiva". Outro conceito relevante é de Coll e Valls (1998, p. 77), que entende os conteúdos procedimentais como um conjunto de "ações ou decisões que compõem a elaboração ou a participação", orientadas a fim de alcançar um objetivo. 
Como especificidade, a presente pesquisa traz consigo a reflexão sobre o processo de aprendizagem em diálogo com as orientações da Base Nacional Comum Curricular (BNCC), que define o conjunto orgânico e progressivo de aprendizagens essenciais, enfatizando a Educação Física como fornecedora de possibilidades para enriquecer a experiência formativa das crianças, jovens e adultos na Educação Básica.

A BNCC sinaliza que "as práticas corporais devem ser abordadas como fenômeno cultural dinâmico, diversificado, pluridimensional, singular e contraditório" (BRASIL, 2017, p. 213). Contudo, como a base pensa e fixa as chamadas aprendizagens essenciais que os estudantes devem se apropriar durante a escolarização básica, seu foco recai bem mais em designar os objetos de conhecimento, assim como as competências e habilidades a serem desenvolvidas em cada nível de ensino. Todavia, os pormenores do processo, ou seja, a construção dos currículos, o planejamento e, consequentemente, as práticas de ensino-aprendizagem, não estão dados no documento, ainda que possam ter indicativos a respeito no texto final da BNCC.

É neste sentido que se pretende, no decorrer deste estudo, apresentar uma alternativa para a avaliação da aprendizagem atrelada à dimensão procedimental, dado que, em acordo com a BNCC e com parte significativa do Movimento Renovador, tem-se uma nova perspectiva na forma de conduzir os processos avaliativo e de ensino-aprendizagem, considerando que a Educação Física oferece diversas possibilidades para o enriquecimento dos alunos. Isso porque essa área dá acesso não somente às práticas corporais em suas formas técnicas (ainda que esta seja uma dimensão impreterível nas aulas de Educação Física), mas também a um vasto universo cultural que compreende a própria técnica como elemento da cultura no sentido de Mauss (2003), bem como possibilita aos alunos compreenderem os aspectos agonísticos, lúdicos, políticos, econômicos e estéticos que circundam o universo das práticas corporais.

Seguindo essa lógica das práticas corporais como expressões da cultura e as orientações da BNCC (BRASIL, 2017), esta pesquisa elencou o 
conteúdo 'Ginástica' como unidade temática na construção de um protocolo de avaliação centrado na dimensão procedimental. No que diz respeito aos conteúdos apontados pela Base, "é importante salientar que a organização das unidades temáticas se baseia na compreensão de que o caráter lúdico está presente em todas as práticas corporais, ainda que essa não seja a finalidade da Educação Física na escola" (BRASIL, 2017, p. 222).

Nessa perspectiva, a BNCC sugere que todas as práticas corporais podem ser trabalhadas incorporando e reconhecendo a dimensão da ludicidade em qualquer etapa e modalidade, seguindo critérios de "progressão do conhecimento" que deverão acompanhar o avanço dos anos escolares dos alunos. No que tange à avaliação, esta deve considerar "elementos específicos das diferentes práticas corporais, as características dos sujeitos e os contextos de atuação, sinalizando tendências de organização dos conhecimentos" (BRASIL, 2017, p. 2019).

Sendo assim, e considerando tanto a recente produção de conhecimento em Educação Física quanto os apontamentos da atual BNCC, questionamo-nos sobre: de que forma a avaliação da aprendizagem em Educação Física, na dimensão procedimental, pode ser desenvolvida na escola dentro de uma concepção progressista e não excludente? Este é o problema que nos conduziu nesta pesquisa.

Construir um protocolo avaliativo como proposta de avaliação da aprendizagem para a área da Educação Física escolar, de acordo com a dimensão procedimental, e tendo a Base Nacional Comum Curricular (BNCC) norteando esse processo de construção, é o objetivo deste estudo, que, para viabilizá-lo, foi necessário organizar este trabalho em quatro momentos: 1. Aspectos Metodológicos; 2. Avaliação na Educação Física escolar; 3. Resultados e Discussões com a apresentação da proposta de protocolo de avaliação; 4. Considerações finais deste estudo. 


\section{ASPECTOS METODOLÓGICOS}

Para alcançar os objetivos indicados, esta pesquisa de cunho qualitativo fez uso de uma revisão bibliográfica em artigos, dissertações e livros que abordam o tema em questão. Tais fontes, que se configuram também como uma etapa do estudo, apresentam-se como mecanismos para a compreensão do debate sobre a avaliação na Educação Física. Com relação ao trabalho de campo, optou-se pela pesquisa-ação, que pode ser definida como:

\footnotetext{
Um tipo de pesquisa com base empírica que é concebida e realizada em estreita associação com uma ação ou com a resolução de um problema coletivo e no qual os pesquisadores e participantes representativos da situação ou do problema estão envolvidos de modo cooperativo ou participativo. (THIOLLENT, 1985, p. 14).
}

Seguindo as orientações da pesquisa-ação, o presente artigo teve o campo de intervenção pedagógica de um dos autores deste texto como lócus privilegiado para a coleta de dados e reflexão sobre a avaliação da aprendizagem. Desse modo, os desafios da prática pedagógica e os limites e possibilidades para a efetivação de uma avaliação emancipadora se transformaram em inquietações e problema de pesquisa, que estudamos sistematicamente à luz de bibliografias especializadas em confronto com o cotidiano da prática educativa.

Após a delimitação das questões e do problema exposto na introdução deste artigo, realizou-se a observação das aulas de Educação Física do $9^{\circ}$ ano do Ensino Fundamental no segundo semestre de 2019, em uma escola de Educação Básica na cidade de Belém, no Estado do Pará. Posteriormente, foi elaborado um protocolo de avaliação do conteúdo de ginástica como proposta para avaliação nas aulas de Educação Física, considerando as dimensões procedimentais $e$ as competências e habilidades da BNCC para os anos finais do ensino fundamental.

Foram observadas uma média de trinta e oito horas-aula em cada turma das quatro que compõem $\circ 9^{\circ}$ ano. A bolsista responsável pelos 
registros de cada aula ministrada pelo(a) docente responsável pelas turmas concentrou-se em registrar, em um caderno de anotações, os seguintes aspectos: os conteúdos trabalhados, a avaliação da aprendizagem aplicada pelo(a) docente - a forma, os procedimentos, os critérios -, a frequência e o pós-avaliação. A bolsista também aplicou um questionário aos alunos com três perguntas: 1. Como você entende a avaliação da aprendizagem nas aulas de Educação Física? 2. Seu professor informou sobre como será sua avaliação? 3. Como você gostaria que fosse sua avaliação em Educação Física? Dos cerca de cem alunos que, na ocasião, compunham $\circ 9^{\circ}$ ano do Ensino Fundamental da escola escolhida como lócus da pesquisa, apenas 38 responderam.

Importante ressaltar que foi enviado aos responsáveis o Termo de Consentimento Livre e Esclarecido (TCLE); do total de 100 termos, foram devolvidos 68. Então, foram entregues 68 questionários aos alunos; desse total, 38 devolveram o questionário respondido.

Após a coleta dos dados, o protocolo de avaliação, construído com onze perguntas que deveriam ser respondidas pelo docente durante a avaliação, foi orientado pelas competências e habilidades da BNCC no que diz respeito ao conteúdo Ginástica, bem como apoiado por uma corrente teórica mais progressista da Educação Física. As respostas SIM, NÃO e PARCIALMENTE devem ser acompanhadas de anotações e comentários sobre a evolução ou não do aluno na aprendizagem do conteúdo trabalhado.

Após a elaboração do protocolo, este foi enviado aos nove docentes de Educação Física da escola selecionada para a pesquisa, para que analisassem, avaliassem e emitissem parecer sugerindo alterações, caso considerassem necessárias, com o intuito de validar o instrumento. Desse total de docentes consultados, seis emitiram parecer com ricas contribuições, as quais foram integralmente incorporadas à versão final do protocolo.

Como este estudo se direciona para uma avaliação da aprendizagem processual seguindo uma linha progressista, distanciando-se de uma 
avaliação tradicional focada na medição, no rendimento esportivo, na aquisição descontextualizada de habilidades motoras e qualidades físicas, que contribuem para a exclusão de alunos e evasão escolar, como assinalam Neuenfeldt e Rataizk (2017), este protocolo avaliativo deve ser orientado no sentido de contribuir para a aprendizagem, podendo ser alterado de acordo com as demandas que se apresentem no dia a dia e na dinâmica de ensino das práticas corporais nas aulas de Educação Física. Conforme evidencia Darido (2012, p. 130), "a avaliação deve mostrar-se útil para as partes envolvidas [...] contribuindo para o autoconhecimento e para a análise das etapas já vencidas, no sentido de alcançar objetivos previamente traçados".

\section{SOBRE A AVALIAÇÃO DA APRENDIZAGEM NA EDUCAÇÃO E NA EDUCAÇÃO FÍSICA ESCOLAR}

Como se discutiu anteriormente, em virtude das conquistas do Movimento Renovador, o debate sobre o processo e as práticas avaliativas na Educação Física ganhou ainda mais elementos, instrumentos e formas a partir da década de 1980, os quais sinalizam para a superação dos modelos tradicionais e de orientação tecnicista (DARIDO, 2012).

Nascimento et al. (2018), com base em estudos de autores como Darido, Bracht e Souza Júnior, revelam as tendências avaliativas em Educação física de acordo com as abordagens pedagógicas que marcaram sua história em determinados períodos. Nesse sentido, tem-se como tendência: 1) "alunos submetidos a testes físicos para verificação de desempenho" numa perspectiva tradicional e descolada de processos educativos, influenciada pelo higienismo, militarismo e esportivismo; 2) "avaliação pautada num espectro humanista-reformista, incutindo-se a verificação e análise pela participação, interesse ou assiduidade", sustentada por uma visão progressista e crítica de Educação e Educação Física.

Assim, segundo Darido (2012, p. 127), "a avaliação é um processo mais amplo que atribuir uma nota. Na verdade, avaliar é um processo que 
procura auxiliar o aluno a aprender, mais e melhor". Na perspectiva da autora, a ação de avaliar precisa superar o binômio reprovação e aprovação, devendo considerar que, muitas vezes, os estudantes trazem para a escola uma gama de experiências com as práticas corporais construídas em outros momentos de suas vidas, que podem perfeitamente enriquecer a dinâmica de aprendizagem de todos, inclusive do professor.

Ainda na óptica de Darido (2012), a Educação Física precisa desempenhar um papel de construção da percepção do aluno no seu próprio aprendizado, já que este deve ser sempre um processo contínuo e diagnóstico da relação do discente com o conhecimento, contando com a participação de professores, família e comunidade escolar. De um ponto de vista geral, o processo de avaliação deve trazer benefícios para todos os envolvidos no trabalho educativo, fazendo professor e aluno entenderem o caminho que deverá ser percorrido na aprendizagem, servindo esta como benefício pedagógico.

Matos e Schuler (2019, p. 408) alertam para a avaliação classificatória, que "atua em uma sociedade que age como uma máquina, isto é, que vive com engrenagens articuladas na produção de indivíduos para o mercado de trabalho". Essa forma de avaliar está atrelada ao tecnicismo, guiada por uma prática pedagógica que induz à reprodução, ao repasse de conteúdos, fomentando e acentuando a hierarquização entre professor e aluno, em que o primeiro deve agir com neutralidade e o segundo como fiel depositário de conteúdos. Nessa perspectiva, "os conhecimentos dos alunos passam a ser medidos por testes padronizados, e os professores passam a ser treinados como técnicos" (MATOS; SCHULER, 2019, p. 409), sendo a escola o espaço propício para fabricar indivíduos aptos e úteis para a manutenção do sistema capitalista.

Ferreira (2009) assinala que o maior erro na área da Educação tem sido o uso da avaliação de forma equivocada e resumida à utilização de testes e provas, cuja ação tem como consequência a classificação dos alunos com base no desempenho nessas atividades. Com isso, aprofunda-se a exclusão no interior da escola, bem como se contribui para a evasão 
escolar, pois, muitas vezes, a prova segue um mero ritualismo (algo protocolar), como se fosse a única forma de verificar aprendizagens. Além desses aspectos, a prova tende a carregar consigo um alto teor emocional, ainda mais quando é utilizada como o único instrumento de avaliação e com foco na aprovação ou reprovação do estudante.

Dessa forma, a avaliação perde seu objetivo de revelar se a aprendizagem foi alcançada, visto que instrumentos como "cola", estado emocional abalado e a atenção voltada em apenas um aspecto desta tornam-se insuficientes para que se tenha um diagnóstico mais preciso sobre o que o aluno apreendeu do conteúdo proposto.

Assim, a avaliação perde suas características formativas, "deixando de ser encarada como um meio de fornecer as informações sobre o processo, tanto para que o professor conheça os resultados de sua ação pedagógica como para o aluno verificar seu desempenho" (FERREIRA, 1992, p. 4). Para Silva (2010, p. 55), a "avaliação em Educação Física Escolar é definida como sendo o processo que permite julgar o ensino-aprendizagem e gerar informações periódicas quantitativas e qualitativas, para o professor e para o aluno".

Um aspecto interessante para essa discussão diz respeito à relação da área da Educação Física com o debate educacional em sentido amplo. Se para a Educação a ideia de avaliação diagnóstica, construtiva e formativa remete quase sempre a um processo crítico e reflexivo de apropriação e construção de conhecimentos que, em geral, são expressos por instrumentos que se referem a uma dimensão eminentemente cognitiva da ação humana, como poderíamos então pensar o processo de ensinoaprendizagem e, por consequência, da avaliação na Educação, considerando a centralidade do corpo e da expressão corporal presente no universo das práticas corporais? Mais ainda, até que ponto é possível pensar em instrumentos que não somente captam aquilo que os alunos podem escrever ou falar sobre um determinado fenômeno, mas também as condutas e expressões que emergem do corpo e que podem sinalizar para diferentes formas de apropriação do universo das práticas corporais? 
Uma pista para essas questões talvez possa ser encontrada no trabalho de Bregolato (2007), em cujo estudo a autora sugere que tanto no processo de planejamento como nas práticas de ensino-aprendizagem os conteúdos da Educação Física sejam pensados a partir de três dimensões, que são: práticas de movimentos corporais, contextualização teórica e princípios de valores e atitudes. Pode ser que um modo interessante de se pensar a ideia de saber procedimental em Educação Física seja pela consideração de que este é um saber que se nutre de reflexão e conceitos, porém, expressa-sa em primazia por via da experiência e dos movimentos corporais.

Darido (2012) destaca que a avaliação da aprendizagem na dimensão procedimental em Educação Física objetiva avaliar se o aluno consegue desenvolver uma determinada habilidade por meio de várias tentativas. Ela ressalta ainda que não se está avaliando a perfeição da técnica do movimento, mas seu esforço e interesse para realizá-lo. Assim, de acordo com a autora, podemos refletir em como seria possível avaliar aprendizagens oriundas do movimento, reconhecendo a presença de fatores como força muscular, resistência, agilidade, ritmo e sentimentos. Trata-se de pensar em como considerar, nas práticas de avaliação, a dimensão relacional, comunicativa e corporal da educação.

Dessa forma, ao avaliar os procedimentos, deve-se observar o saberfazer numa perspectiva menos tecnicista e mais progressista, considerando a evolução das capacidades físicas e das habilidades motoras dos alunos em relação à sua bagagem cultural, bem como ao repertório de movimentos que possuía antes de ter acesso de modo sistematizado à determinada prática corporal na escola. A partir dessa compreensão, há de se questionar se a Educação Física não deixou de proporcionar aos alunos vivências dentro da cultura corporal do movimento.

Como bem pontua Zabala (1999), na avaliação procedimental, é importante que o aluno incorpore o saber-fazer, desde um simples ato como abrir e fechar uma porta até um saber-fazer mais elaborado, como a escrita. Darido $(2012$, p. 128) assinala que, na perspectiva tradicional de avaliação em Educação Física na escola, no que diz respeito ao saber-fazer, "o aluno 
era avaliado por testes físicos ou pelo seu desempenho nos esportes". Consequentemente, a nota é correlata do grau de "perfeição" na execução de gestos técnicos, condutas táticas e de movimentos padronizados do esporte de alto rendimento. Portanto, podemos entender que "avaliar em Educação Física consiste em reconhecer, diagnosticar, e valorizar o desenvolvimento da expressão individual e a cultura pessoal, proporcionando a aprendizagem e formação do educando" (NEUENFELDT; RATAIZK, 2017, p. 17).

\section{RESULTADOS E DISCUSSÕES}

Como anunciado na metodologia deste estudo, foram realizadas três perguntas aos alunos em forma de questionário, o qual foi entregue aos discentes em que os responsáveis devolveram o termo de Consentimento Livre e Esclarecido. As perguntas foram: 1. Como você entende a avaliação da aprendizagem nas aulas de Educação Física? 2. Seu professor informou sobre como será sua avaliação? Como você gostaria que fosse sua avaliação em Educação Física? Vimos a necessidade de aplicar esse questionário como suporte e subsídios para a construção do protocolo de avaliação. Precisávamos diagnosticar o entendimento dos alunos sobre a avaliação em Educação Física e suas perspectivas.

Após a compilação das respostas da primeira pergunta, pudemos aferir que, de uma forma geral, os alunos entendem a avaliação da aprendizagem em Educação Física como um momento em que são submetidos a provas e testes para saberem se seu desempenho nas aulas práticas foi ruim, bom ou ótimo. Quanto às respostas da segunda pergunta, $60 \%$ responderam que nunca sabem como serão avaliados. Os $40 \%$ restantes acham que são avaliados pelo seu desempenho nas aulas práticas para saber se possuem ou não habilidades para a prática dos esportes. Também citaram que, durante as aulas, o(a) docente fala para participarem e não faltarem porque vale ponto em Educação Física. Sobre as respostas da terceira pergunta, $70 \%$ dos alunos gostariam que não houvesse avaliação em Educação Física, já que fazem muitas atividades avaliativas e trabalhos 
em muitas disciplinas. Os outros $30 \%$ afirmaram que não querem prova escrita nem prática, que gostariam de ser avaliados apenas pela sua frequência nas aulas.

Essas respostas nos levam a refletir sobre o conceito captado pelos alunos em relação à avaliação da aprendizagem em Educação Física e o quanto precisamos mudar essa realidade, pois, como enfatiza Darido (2012, p. 131), a avaliação precisa ser praticada e entendida como "um processo que se relaciona não só com o esforço do aluno de aprender, mas também com o do professor de mudar suas práticas, caso os alunos apresentem dificuldades de aprendizagem".

A respeito das respostas da primeira pergunta, os alunos entendem a avaliação em uma concepção tradicional, a qual prioriza a medição, a aplicação de provas com sentido classificatório. Para Matos e Schuler (2019), esse entendimento parece ainda ser dominante na ação pedagógica. Dessa forma, destacamos a importância de a avaliação ser entendida como um processo, o qual deve estar claro para os alunos, como se evidencia na segunda pergunta, em que os alunos afirmam desconhecer a forma que serão avaliados. Acerca disso, Darido (2012) enfatiza que é primordial os alunos terem conhecimento, desde o primeiro dia de aula, de como acontecerá a avaliação durante o ano letivo.

$\mathrm{Na}$ terceira pergunta, os alunos confessam sua aversão pela avaliação, provavelmente por desconhecerem o real sentido dela, que, segundo Darido (2012, p. 130), é "oferecer ao professor elementos para uma reflexão contínua sobre a sua prática, no que se refere à escolha de competências, objetivos, conteúdos e estratégias", ou seja, a avaliação deve funcionar como uma constante reflexão sobre e para a melhoria da prática de ensino.

Mediante as respostas apresentadas, faz-se necessário entender que, para conseguirmos mudar a concepção dos alunos sobre a avaliação em Educação Física, precisaremos, em primeiro lugar, mudar nossa própria concepção sobre como e o que avaliar, sobre quem estamos avaliando e 
para que estamos avaliando. As respostas dos discentes são uma leitura do que vivenciam, do que nós, docentes, entregamos a eles.

De posse dessas respostas e do acompanhamento das aulas, o protocolo avaliativo em Educação Física foi construído, o qual teve como finalidade cumprir com os objetivos desta pesquisa e levantar a questão da falta ou deficiência de uma orientação no processo de avaliação da aprendizagem na referida área. Baseando-nos nas competências e habilidades expostas na BNCC para $\circ 9^{\circ}$ ano do Ensino Fundamental, escolhemos a Ginástica como unidade temática para este nível de ensino, um dos conteúdos da Educação Física indicados pela BNCC, que a subdivide em Ginástica de Condicionamento Físico e Ginástica de Conscientização Corporal.

O protocolo é constituído por 11 (onze) questões sobre os conhecimentos que devem ser construídos e apreendidos pelos alunos. Cada pergunta apresentada faz paralelo às competências específicas para Educação Física segundo a BNCC. Portanto, a cada pergunta, fez-se uma projeção do que a base se refere, fundamentando-se em alguns autores que norteiam o tema.

Na pergunta de número 1, tem-se como relevante a compreensão da origem da cultura corporal a partir do movimento do próprio aluno. Para Soares et al. (1992), a Educação Física na escola é entendida como uma área do conhecimento que se dedica aos estudos e desenvolvimento da cultura corporal, por meio de práticas corporais como jogo, esporte, dança, capoeira e ginástica. De acordo com a BNCC (BRASIL, 2017, p. 213), "O movimento humano está sempre inserido no âmbito da cultura e não se limita a um deslocamento espaço-temporal de um segmento corporal ou de um corpo todo".

A questão de número 2 traz ênfase para as práticas corporais e as estratégias para a aprendizagem. Segundo a própria BNCC (BRASIL, 2017, p. 213), "é fundamental frisar que a Educação Física oferece uma série de possibilidades para enriquecer a experiência das crianças, jovens e adultos na Educação Básica, permitindo acesso a um vasto universo cultural". 
A questão de número 3 apresenta a relação da ginástica com a qualidade de vida (saúde/doença). Conforme Taffarel (2010), o professor de Educação Física que deseja trabalhar de modo crítico com o tema da saúde necessita primeiramente rever o seu enfoque teórico para abordar conceitos como: saúde, doença e atividade física. Para isso, é preciso compreender a construção sócio-histórica da cultura corporal e da saúde, o que implica pensar para além das lentes biologicistas, que quase sempre concebem saúde como ausência de doença ou como alguma coisa que pode ser adquirida somente por via da prática de atividade física.

Ao englobar as questões 4, 5 e $\mathbf{6}$ do protocolo de avaliação, que diz respeito aos cuidados de si e de seus colegas, evidenciam-se a ginástica como elemento da prática corporal e a autonomia do aluno relacionada às atividades da modalidade apresentada. Acerca disso, ressalta-se, na BNCC, que as práticas corporais nas aulas de Educação Física não são estanques, pois constituem um fenômeno cultural que é vivo, está à disposição de todos e, ao mesmo tempo, é único e contraditório. Imbuído desse entendimento, é imprescindível aos alunos o acesso a conhecimentos que possam "ampliar sua consciência a respeito de seus movimentos e dos recursos para o cuidado de si e dos outros e desenvolver autonomia para apropriação e utilização da cultura corporal de movimento" (BRASIL, 2017, p. 213).

Associando as questões $\mathbf{7 , 8}$ e $\mathbf{9}$ ao que a BNCC se refere à consciência corporal enquanto elemento social de direito e autenticidade individual do aluno, considerada por Brito (1996, p. 41) como "um processo mental e a percepção mental da atividade corporal, em que ser consciente é perceber as sensações produzidas pelo corpo", torna-se importante olhar e pensar o aluno em todas as suas dimensões, haja vista que "cada prática corporal propicia ao sujeito o acesso a uma dimensão de conhecimento e de experiência aos quais ele não teria de outro modo" (BRASIL, 2017, p. 14). É por meio da prática corporal que o aluno vai tomando conhecimento e consciência de seu corpo, manifestando sua subjetividade como um ser 
histórico. Assim, faz-se imprescindível que ele tenha acesso ao maior leque possível de experiências e vivências práticas.

A ginástica está na BNCC como uma das unidades temáticas de ensino, estando classificada em: ginástica geral, ginástica de condicionamento físico e ginástica de conscientização corporal, sendo que, para os anos finais do ensino fundamental, estão as duas últimas classificações como conteúdo. Portanto, a questão de número $10 \mathrm{faz}$ referência à experimentação da ginástica de conscientização corporal, que a BNCC (BRASIL, 2017, p. 218) define como práticas que "empregam movimentos suaves e lentos, tal como a recorrência a posturas ou à conscientização de exercícios respiratórios, voltados para obtenção de uma melhor percepção sobre o próprio corpo".

Por conseguinte, tem-se a questão de número 11, que traz a experimentação das semelhanças e diferenças da ginástica de condicionamento físico e de conscientização corporal por parte do aluno. Como foi citado acima, a BNCC define as ginásticas de conscientização corporal, assim como também define as ginásticas de condicionamento físico, pontuando que estas "se caracterizam pela exercitação corporal orientada à melhoria do rendimento, à aquisição e à manutenção da condição física individual ou à modificação da composição corporal" (BRASIL, 2017, p. 217).

No quadro 1 é apresentado o protocolo de avaliação como resultado da construção dos aspectos que norteiam a avaliação procedimental, considerando as competências e os conteúdos da BNCC. A partir dos pareceres enviados pelos docentes de Educação Física da escola em que foi realizada a pesquisa, bem como da construção e reflexão teórica sobre o processo de avaliação da aprendizagem, o protocolo foi elaborado para potencializar o registro e a avaliação a respeito da dimensão procedimental do conteúdo "ginástica" com turmas do $9^{\circ}$ ano do Ensino Fundamental.

Optamos em promover primeiro a discussão das questões que compõem o protocolo avaliativo para, então, apresentá-lo. Como já foi dito anteriormente, o intuito é proporcionar um direcionamento aos docentes de 
Educação Física no que concerne à avaliação da aprendizagem, sendo esta tratada neste texto em seu viés progressista, distanciando-se de uma avaliação punitiva e excludente.

QUADRO 1 - Protocolo de Avaliação em Educação Física

\begin{tabular}{|c|c|c|}
\hline CONTEÚDO: GINÁSTICA & $\begin{array}{c}\text { Ginástica de } \\
\text { Condicionamento } \\
\text { Físico }\end{array}$ & $\begin{array}{c}\text { Ginástica } \\
\text { de } \\
\text { Conscientização } \\
\text { Corporal }\end{array}$ \\
\hline \multicolumn{3}{|l|}{ ALUNO: } \\
\hline \multicolumn{3}{|l|}{ TURMA: } \\
\hline \multicolumn{3}{|l|}{$\begin{array}{l}\text { 1. Expressou corporalmente a } \\
\text { origem da cultura corporal e } \\
\text { suas dimensões na sociedade? }\end{array}$} \\
\hline \multicolumn{3}{|l|}{$\begin{array}{l}\text { 2. Empregou estratégias } \\
\text { corporais para resolver os } \\
\text { desafios e aumentar as } \\
\text { possibilidades } \\
\text { aprendizagem das práticas do } \\
\text { conteúdo? }\end{array}$} \\
\hline \multicolumn{3}{|l|}{$\begin{array}{l}\text { 3. Possui novas ações corporais } \\
\text { sobre a relação da ginástica, } \\
\text { sua prática e a implicação no } \\
\text { processo de qualidade de } \\
\text { vida? }\end{array}$} \\
\hline \multicolumn{3}{|l|}{$\begin{array}{llr}\text { 4. Respeitou seus colegas de } \\
\text { turma na compreensão e } \\
\text { execução } & \text { individual } & \text { do } \\
\text { conteúdo? } & & \\
\end{array}$} \\
\hline \multicolumn{3}{|l|}{$\begin{array}{l}\text { 5. Expressou a ginástica como } \\
\text { elemento da prática corporal? }\end{array}$} \\
\hline \multicolumn{3}{|l|}{$\begin{array}{l}\text { 6. Usufruiu das práticas do } \\
\text { conteúdo de } \\
\text { autônoma? }\end{array}$} \\
\hline \multicolumn{3}{|l|}{$\begin{array}{l}\text { 7. O conteúdo desenvolveu no } \\
\text { aluno consciência de que o } \\
\text { acesso às práticas corporais é } \\
\text { de direito aos cidadãos? }\end{array}$} \\
\hline \multicolumn{3}{|l|}{$\begin{array}{l}\text { 8. O aluno criou ou elaborou } \\
\text { movimentos e sequências não } \\
\text { oficiais à modalidade? }\end{array}$} \\
\hline \multicolumn{3}{|l|}{$\begin{array}{l}\text { 9. Identificou e demonstrou a } \\
\text { potencialidade e os limites do } \\
\text { seu corpo? }\end{array}$} \\
\hline \multicolumn{3}{|l|}{$\begin{array}{l}\text { 10. Experimentou na ginástica a } \\
\text { conscientizacão corporal? }\end{array}$} \\
\hline 11. Experimentou as diferenças & & \\
\hline
\end{tabular}


e semelhanças entre ginástica de condicionamento físico e conscientização corporal?

Fonte: Elaboração dos autores (2021).

\section{CONCLUSÕES}

O desenvolvimento do tema desta pesquisa proporciona o envolvimento com as questões que implicam no ensino-aprendizagem e nos processos de avaliação no cotidiano das escolas, em particular nas aulas de Educação Física.

Após os pareceres dos docentes da escola lócus da pesquisa e o conteúdo de estudos sobre o tema trabalhado, ficou evidente a importância da avaliação, a necessidade e responsabilidade que ela possui para com os indivíduos ligados ao processo de ensino-aprendizagem. Chaves (1999) pontua que o processo de ensino-aprendizagem tem como característica principal a relação pedagógica que acontece entre o docente, o aluno e o objeto de conhecimento.

Percebe-se que a avaliação muitas vezes ainda acontece de forma tradicional, passando para os alunos a impressão de que se trata de prova e notas. Portanto, a partir desta pesquisa, notou-se o empenho de muitos autores em esclarecer que a avaliação da aprendizagem precisa romper as barreiras do tradicionalismo e emergir de modo amplo e diversificado. É possível perceber que os desafios para o ensino são constantes e que muito ainda se tem para desenvolver, como assinala Silva (2010, p. 71):

\footnotetext{
A educação física como um todo não tem acompanhado o progresso que a comunidade escolar deseja que ela mostre, estreitando a relação entre a teoria e a prática pedagógica, inovando, criando novos modelos, estratégias, metodologias e conteúdos, que possam contribuir na formação cultural da sociedade contemporânea como um todo.
}

A pesquisa trouxe o ensino-aprendizagem a partir das competências da BNCC, que é a favor do protagonismo dos alunos e aponta habilidades e competências que eles devem desenvolver durante o processo de 
escolarização básica. Desse modo, o entendimento é de que a Educação Física, em seus processos de ensino-aprendizagem, proporciona aos professores e alunos desenvolvimentos em suas formas de ensinar e aprender, e que se pode, dentro desse processo, englobar a igualdade e equidade nos modos de avaliação.

Considera-se, a partir dos resultados obtidos por meio do protocolo de avaliação, que ainda há esforço e conscientização por parte de todos os envolvidos para que o processo de avaliação seja tratado de forma inovadora, gerando mudanças positivas nas escolas e na educação como um todo. Desse modo, diante da perspectiva de que a avaliação, em suas dimensões sendo trabalhadas em conjunto, traz benefícios aos envolvidos e é uma eficiente ferramenta quanto ao processo de ensino-aprendizagem, enfatiza-se que pesquisas voltadas ao assunto oferecem grande contribuição e discussão, trazendo ideias novas e agregando no aperfeiçoamento da prática do ensino, proporcionando, assim, qualidade e melhorias aos professores, alunos, comunidade escolar e sociedade.

Ressaltamos que esse protocolo deve ser entendido como um norte, um orientador e não como algo fechado e condensador de todo conhecimento que o aluno pode adquirir em relação à ginástica. Cada docente deverá adequar esse protocolo de acordo com a realidade e as vivências de seus alunos. Outrossim, ele deve funcionar como uma referência se o aluno alcançou ou não os objetivos de aprendizagem do conteúdo trabalhado, com o intuito de que o professor possa ter um diagnóstico da aprendizagem para intervir de forma propositiva para que o estudante consiga apreender os conhecimentos inerentes a esse conteúdo. É imprescindível que esse protocolo rompa completamente com os ditames de uma avaliação tradicional que classifica e pune, devendo focar na aprendizagem.

Importante frisar que se faz urgente a necessidade de reflexão da comunidade escolar sobre a avaliação da aprendizagem em Educação Física a fim de torná-la não excludente, reconhecendo e respeitando toda a bagagem cultural, social e as experiências motoras trazidas e construídas 
pelos alunos, bem como pensar e entender o aluno em todas as suas dimensões. Para isso, é de suma importância que as aulas sejam construídas com objetivos claros, que os alunos tenham pleno entendimento dos conteúdos que estudarão e da forma como serão avaliados, sendo que o resultado dessa avaliação, principalmente se negativo, precisa retornar ao aluno em forma de uma nova metodologia, até que ele entenda e apreenda $\circ$ conhecimento que está sendo compartilhado sobre determinado conteúdo.

Por último, frisamos que esta pesquisa encontra seu limite justamente na apresentação do protocolo como uma ferramenta para registro e avaliação da aprendizagem procedimental. Em outro momento, pretendemos apresentar resultados mais efetivos a partir dos registros realizados com turmas da Educação Básica por via do referido protocolo. Destacamos também que podemos perspectivar a construção de protocolos e instrumentos de avaliação que registrem a interação entre teoria e prática nas aulas de Educação Física, fazendo com que os saberes procedimentais se conectem cada vez mais a um campo conceitual.

\section{REFERÊNCIAS}

BRASIL. Parâmetros curriculares nacionais: educação física. Brasília: MEC/SEF, 1998. Disponível em: http://portal.mec.gov.br/seb/arquivos/pdf/fisica.pdf. Acesso em: 14 abr. 2019.

BRASIL. Base Nacional Comum Curricular: educação é a base. Linguagens educação física ensino fundamental, 2017. Disponível em: http://basenacionalcomum.mec.gov.br/images/BNCC_publicacao.pdf Acesso em: 11 abr. 2019.

BRASIL. Lei de diretrizes e bases da educação nacional. Brasília: Senado Federal, Coordenação de Edições Técnicas, 2017. Disponível em: http://www2.senado.leg.br/bdsf/bitstream/handle/id/529732/lei_de_diretrizes _e_bases_led.pdf. Acesso: 29 abr. 2019.

BREGOLATO, R. Cultura corporal do jogo. São Paulo: Ícone, 2007.

BRITO, C. L. Repensando a educação física. Rio de Janeiro: Sprint,1996. 
CHIZZOTTI, A. Pesquisa qualitativa em ciências humanas e sociais. 2. ed. Petrópolis, RJ: Vozes, 2008.

CHAVES, E. O. C. Tecnologia na educação, ensino à distância e aprendizagem mediada pela tecnologia: conceituação básica. Revista de Educação, Campinas, v. 3, n. 7, p. 29-43, nov. 1999.

COLL, C.; VALLS, E. A aprendizagem e o ensino de procedimentos. In: COLL, C; POZO, J. I.; SARAIBA, B. Reforma: ensino e aprendizagem de conceitos, procedimentos e atitudes. Porto Alegre: Artemed, 1998. p. 73-118.

DARIDO, S. A Avaliação da educação física na escola. Caderno de formação de professores didática geral. São Paulo: Cultura Acadêmica, 2012, p. 127-140, v. 16.

DARIDO, S. Educação Física na escola: questões e reflexões. Rio de Janeiro: Guanabara Koogan, 2003.

DEMO, P. Avaliação qualitativa: polêmicas do nosso tempo. 8. ed. Campinas, SP: Autores Associados, 2005.

FARIA JÚNIOR, A. G.; FARINATTI, P de T. V. Pesquisa e produção do conhecimento em educação física. Rio de Janeiro: Ao Livro Técnico, 1992.

FERREIRA, L. M. S. Retratos da avaliação: conflitos, desvirtuamentos e caminhos para a superação. 3. ed. Porto Alegre: Mediação, 2009.

FERREIRA, P. R. P. Avaliar: um ato que exige mudança. AMAE Educando, abr., 1992.

FREIRE, J. B. Educação de corpo inteiro. São Paulo: Scipione, v. 4, 1989.

FREIRE, P. Pedagogia da autonomia: saberes necessários à prática educativa. 38. ed. São Paulo: Paz e Terra, 2008.

FREIRE, P. Pedagogia do oprimido. 63. ed. Rio de Janeiro/São Paulo: Paz e Terra, 2017.

FREITAS, L. C. Crítica da Organização do Trabalho Pedagógico e da Didática. 1994. 305 f. Tese (Livre Docência em Educação) - Universidade Estadual de Campinas. São Paulo/SP, 1994.

FUZII, F. T.; SOUZA NETO, S. Formação de professores e avaliação: a educação física em destaque. São Paulo: Cultura Acadêmica, 2013. 
GONZÁLEZ, F. J.; FENSTERSEIFER, P. E. Entre o "não mais" e o "ainda não": pensado saídas do não lugar da Educação Física escolar. Cadernos de Formação RBCE, p. 9-24, set., 2009.

HOFFMANN, J. Avaliação: mito e desafio: uma perspectiva construtivista. Porto Alegre: Educação \& Realidade, 1991.

HOFFMANN, J. Avaliação: mito e desafio uma perspectiva construtivista. 39. ed. Porto Alegre: Mediação, 2005.

HOFFMANN, J. Avaliar para promover: as setas do caminho. 17. ed. Porto Alegre: Mediação, 2018.

LIBÂANEO, J. C. Didática. São Paulo: Cortez, 1994.

MATOS, S. R. L.; SCHULER, B. Discursos da avaliação escolar na contemporaneidade. Revista Exitus, Santarém/PA, v. 9, n. 1, p. 397 -425, jan./mar. 2019.

MAUSS, M. Sociologia e antropologia. São Paulo: Cosac Naify, 2003.

NEUENFELDT, D. J. Instrumentos e critérios de avaliação utilizados pelos professores de Educação Física nos anos finais do ensino fundamental.

Kinesis, Santa Maria, v. 35, n. 2, p. 14-22, maio/ago. 2017.

OLIVEIRA, I. B.; FRIZZO, G. F. E. Avaliação na Educação Física escolar: um estudo com docentes em diferentes períodos de experiência profissional. Kinesis, Santa Maria, v. 36, n. 2, p. 64-72, maio/ago. 2018.

SILVA, J. F.; BANKOFF, A. D. P. Métodos de avaliação em educação física no ensino fundamental. Conexões, Campinas, v. 8, n. 1, p. 54-74, jan./abr. 2010.

SOARES, C. L. et al. Metodologia do ensino da Educação Física. São Paulo: Cortez, 1992.

TAFFAREL, C. Z. Sobre o sistema de complexos homem-esporte-saúde: reflexões a partir de contribuições da Alemanha. In: MATIELLO JUNIOR, E.; CAPELA, P.; BREILH, J. Ensaios alternativos latino-americanos de educação física, esportes e saúde. Florianópolis: Copiart, 2010. p. 159-183.

THIOLLENT, M. Metodologia da pesquisa-ação. São Paulo: Cortez, 1985. Pesquisa-ação nas organizações. São Paulo: Atlas, 1997.

VENTURINI, G. R. de O. et al. A importância da ludicidade na Educação Infantil para o desenvolvimento das habilidades motoras. Revista Digital, Buenos Aires, v. 15, n. 145, jun. 2010. Disponível em: http://efdeportes.com. Acesso em: 04 ago. 2020. 
ZABALA, A.; ROSA, E. Como trabalhar os conteúdos procedimentais em aula. 2. ed. Porto Alegre: Artmed, 1999.

Revisor de língua portuguesa e das regras da ABNT: Elizier Júnior Araújo dos Santos - Professor e revisor de texto. Mestre em Estudos literários (PPGL-UFPA).

Recebido em: 11 de dezembro de 2020.

Aprovado em: 02 de maio de 2021. Publicado em: 03 de maio de 2021.

(c) (i) 